RUNNING HEAD: Revised Sociosexual Orientation Inventory

\title{
The revised Sociosexual Orientation Inventory
}

\author{
Lars Penke \\ Centre for Cognitive Aging and Cognitive Epidemiology, \\ Department of Psychology, University of Edinburgh, 7 George Square, \\ Edinburgh, EH8 9JZ, UK \\ Tel.: +44 131 6511304; fax: +44 131 6503461; email address: lars.penke@ed.ac.uk
}

Word count: 1,300

8 references, 1 table

To appear as:

Penke, L. (in press). The revised Sociosexual Orientation Inventory. In T. D.

Fisher, C. M. Davis, W. L. Yarber \& S. L. Davis (Eds.): Handbook of sexualityrelated measures ( $3^{\text {rd }}$ Ed.). Taylor \& Francis. 


\section{Purpose:}

The construct of sociosexuality or sociosexual orientation captures individual differences in the tendency to have casual, uncommitted sexual relationships. The term was introduced by Alfred Kinsey, who used it to describe the individual differences in sexual permissiveness and promiscuity that he found in his groundbreaking survey studies on sexual behavior (Kinsey, Pomeroy, \& Martin, 1948; Kinsey, Pomeroy, Martin, \& Gebhard, 1953). The amount of scientific research on sociosexuality increased markedly when Simpson and Gangestad (1991) published the Sociosexual Orientation Inventory (SOI), a 7-item self-report questionnaire that assesses sociosexual orientations along a single dimension from "restricted" (indicating a tendency to have sex exclusively in emotionally close and committed relationships) to "unrestricted" (indicating a tendency for sexual relationships with low commitment and investment, often after short periods of acquaintance and with changing partners). On average, men tend to be more unrestricted than women in their sociosexual orientations, though there are also large individual differences within both sexes (Schmitt, 2005). The SOI has been successfully applied in over 50 published studies from fields as diverse as social, personality, and evolutionary psychology, sexuality research, gender studies, biological anthropology, and crosscultural research (Simpson, Wilson, \& Winterheld, 2004).

Despite its popularity, the SOI has repeatedly been criticized (Asendorpf \& Penke, 2005; Penke \& Asendorpf, 2008; Townsend, Kline, \& Wasserman, 1995; Voracek, 2005; Webster \& Bryan, 2007). Conceptually, it has been doubted that a single unitary dimension accurately reflects individual differences in sociosexuality. Psychometrically, the SOI has received criticism for its sometimes low internal consistency, multifactorial structure, skewed score distribution, open response items that invite exaggerated responses, multiple alternative scoring methods that yield incoherent results, and the formulation of one item (number 4) that makes the SOI inappropriate for singles. The revised Sociosexual Orientation Inventory (SOI-R) is a 
9-item self-report questionnaire that was developed to fix all these issues (Penke \& Asendorpf, 2008). It assesses three facets of sociosexuality: Past Behavior in terms of number casual and changing sex partners, the explicit Attitude towards uncommitted sex, and sexual Desire for people with whom no romantic relationship exists.

\section{Description:}

The SOI-R consists of nine items, three for each of the three facets. All are answered on rating scales. The first two items of the Behavior facet are taken from the original SOI. They ask for the number of sexual partners in the last 12 months and the lifetime number of "one night stands". The third behavioural item assesses the number of partners with whom one had sex despite a lack of long-term relationship interest. Similarly, the first two Attitude items (asking for acceptance of sex without love and for comfort with casual sex) are identical with two items from the SOI, while a new item (asking for requiring the prospect of a long-term relationship before consenting to sex) replaces an SOI attitude item with overly long and complicated text. Finally, three new items assess the Desire facet, which was not very well represented in the original SOI (Penke \& Asendorpf, 2008). They ask for the frequency with which one experiences spontaneous sexual fantasies or sexual arousal when encountering people in everyday life with whom no committed romantic relationship exists.

In a series of studies, the SOI-R items were chosen from a pool of 47 items using exploratory factor analysis and item analysis (Penke, 2006). Confirmatory factor analysis supported that they represent distinctive facets of sociosexuality with low to moderate positive intercorrelations (.17 to .55$)$. The correlation between the Attitude and Behavior facet was significantly larger in women than in men, but otherwise the factorial structure is invariant between the sexes, showing that the SOI$\mathrm{R}$ is equally appropriate for men and women (Penke \& Asendorpf, 2008). 
An analysis of 8,522 participants from an online study indicates that the SOI$\mathrm{R}$ is appropriate for individuals of any normal-range educational level, including hetero-, bi- and homosexuals, singles and individuals of any relationship/marital status, and at least the age range of 18 to 60 years (Penke, 2006; data partly available on www.larspenke.eu/soi-r/). However, some facets do not work very well for sexually inexperienced and asexual individuals.

\section{Response Mode and Timing:}

All items of the SOI-R use Likert-type rating scales with the same number of response alternatives, which makes the SOI-R appropriate for both paper-and-pencil and online studies. Two alternative response scale formats exist for the SOI-R, one with nine and the other with five response alternatives. Both show comparable psychometric properties. The 9-point response scale was developed to allow for combining the SOI-R with the original SOI (for details, see Penke \& Asendorpf, 2008). However, for the majority of applications I recommend the 5-point response scale, since most subjects (especially non-students) find it easier to discriminate between five than between response alternatives. The SOI-R takes 1-2 minutes to complete.

\section{Scoring:}

For items 1 to 3 , values of 1 to 5 (5-point response scale) or values of 1 to 9 (9-point response scale) should be assigned to the responses. Thus, all nine items have values from 1 to 5 (5-point scale) or 1 to 9 (9-point scale). Item 6 should be reverse-keyed. Items 1 to 3 are aggregated (summed or averaged) to form the Behavior facet, items 4 to 6 form the Attitude facet, and items 7 to 9 form the Desire facet. Finally, all nine items can be aggregated to form a full scale score that represents the global sociosexual orientation, similar to the full score of the original SOI. Since most SOI-R scores (except Behavior) usually show marked sex 
differences, results should be analysed separately for men and women, or alternatively sex should be statistically controlled in all analyses. Descriptive statistics for average facet and full scale scores for both response formats can be found in Table 1.

Reliability:

As can be seen in Table 1, the SOI-R facet and total scores show good internal consistencies for both response formats. Additionally, all scores except the Desire facet show good 1-year retest stability, at least when the 9-point scale is used. The lower retest stability of the Desire facet appears to relate to its transactions with romantic relationship status, with women in particular showing more restrictive desires when starting a new relationship and less restrictive desires when separating (see Penke \& Asendorpf, 2008).

Validity:

In two large studies, Penke and Asendorpf (2008) showed that the SOI-R full scale score and the SOI showed very similar relationships to established correlates of the sociosexuality, including sex differences, past and future relationship and sexual behaviors, infidelity, mate choice preferences, sex drive, personality traits like shyness and sensation seeking, and flirting behavior towards an attractive oppositesex stranger. Thus, there is strong evidence that the SOI-R offers the same predictive validity that has been shown for the SOI (Simpson et al., 2004).

However, more detailed analyses revealed a highly distinctive pattern of relationships for the three SOI-R facets, supporting their discriminant validity. For example, sex differences were pronounced for Desire, mediocre for Attitude and nonexistent for Behavior (Table 1). Only Desire made unique contributions to the prediction of past sexual and relationship behaviors, observer-rated attractiveness, self-perceived mate value and female flirting behavior, while Attitude appeared 
responsible for the effects of sociosexuality on mate preferences, assortative mating, and a romantic partner's flirtatiousness outside the relationship, and Desire had strong independent effects on relationships with sex drive, relationship quality, and male flirting behavior. Furthermore, Behavior and Desire, but not Attitude, predicted the number of sexual partners and changes in romantic relationship status over the next 12 month. Thus, Behavior, Attitude, and Desire apparently reflect rather unique components of sociosexuality that should be studied separately in order to understand the dynamics that underlie sociosexual orientations.

Other Information:

The SOI-R can freely be used for research purposes. The items of 10 different language versions (Chinese, Dutch, Icelandic, Italian, English, French, German, Malaysian, Spanish, and Swedish) can be downloaded from www.larspenke.eu/soi-r/. 


\section{$\underline{\text { References }}$}

Asendorpf, J. B., \& Penke, L. (2005). A mature evolutionary psychology demands careful conclusions about sex differences. Behavioral and Brain Sciences, 28, 275-276.

Penke, L. (2006). Development of the revised Sociosexual Orientation Inventory (SOI-R). Unpublished manuscript, Institute of Psychology, Humboldt University of Berlin.

Penke, L., \& Asendorpf, J. B. (2008). Beyond global sociosexual orientations: A more differentiated look at sociosexuality and its effects on courtship and romantic relationships. Journal of Personality and Social Psychology, 95, 1113-1135.

Schmitt, D. P. (2005). Sociosexuality from Argentina to Zimbabwe: A 48-nation study of sex, culture, and strategies of human mating. Behavioral and Brain Sciences, 28, 247-275.

Simpson, J. A., \& Gangestad, S. W. (1991). Individual differences in sociosexuality: Evidence for convergent and discriminant validity. Journal of Personality and Social Psychology, 60, 870-883.

Simpson, J. A., Wilson, C. L., \& Winterheld, H. A. (2004). Sociosexuality and romantic relationships. In J. H. Harvey, A. Wenzel, \& S. Sprecher (Eds.), Handbook of sexuality in close relationships (pp. 87-111). Mahwah: Erlbaum.

Townsend, J. M., Kline, J., \& Wasserman, T. H. (1995). Low-investment copulation: Sex differences in motivations and emotional reactions. Ethology and Sociobiology, 16, 25-51.

Voracek, M. (2005). Shortcomings of the Sociosexual Orientation Inventory: Can psychometrics inform evolutionary psychology? Behavioral and Brain Sciences, 28, 296-297.

Webster, G. D., \& Bryan, A. (2007). Sociosexual attitudes and behaviors: Why two factors are better than one. Journal of Research in Personality, 41, 917-922. 


\section{$\underline{\text { Tables }}$}

Table 1. Descriptive statistics, reliabilities and effect sizes for sex differences for both SOI-R response scale formats.

\begin{tabular}{lccccccc}
\hline & & $N$ & Cronbach's & $r_{\text {tt }}$ & $M$ & $S D$ & Cohen's \\
& & & $\alpha$ & $(1$ year $)$ & & & $d$ \\
\hline 5-point scale & & & & & & & \\
SOI-R Behavior & male & 2728 & .85 & - & 2.19 & 1.10 & .00 \\
& female & 5821 & .78 & - & 2.19 & .95 & \\
SOI-R Attitude & male & 2706 & .81 & - & 3.54 & 1.18 & .45 \\
& female & 5794 & .81 & - & 3.01 & 1.20 & \\
SOI-R Desire & male & 2687 & .82 & - & 3.45 & 1.01 & .86 \\
& female & 5748 & .82 & - & 2.61 & .96 & \\
SOI-R & male & 2647 & .82 & - & 3.07 & .82 & .57 \\
& female & 5632 & .83 & - & 2.60 & .80 &
\end{tabular}

\section{9-point scale}

$\begin{array}{llcccccc}\text { SOI-R Behavior } & \text { male } & 1026 & .85 & .83 & 2.76 & 1.83 & .06 \\ & \text { female } & 1682 & .84 & .86 & 2.65 & 1.73 & \\ \text { SOI-R Attitude } & \text { male } & 1026 & .87 & .73 & 6.42 & 2.33 & .43 \\ & \text { female } & 1682 & .83 & .79 & 5.41 & 2.37 & \\ \text { SOI-R Desire } & \text { male } & 1026 & .86 & .68 & 5.62 & 1.91 & .86 \\ & \text { female } & 1682 & .85 & .39 & 3.96 & 1.94 & \\ \text { SOI-R } & \text { male } & 1026 & .83 & .83 & 4.93 & 1.50 & .61 \\ & \text { female } & 1682 & .83 & .78 & 4.01 & 1.52 & \end{array}$

Note: $r_{\mathrm{tt}}=$ test-retest correlation. The results for the 5-point response scale are from an unpublished online study (Penke, 2006). The results for the 9-point response scale are from Study 1 in Penke and Asendorpf (2008). More detailed results, split by subsamples, can be found on www.larspenke.eu/soi-r/. 


\section{The revised Sociosexual Orientation Inventory (SOI-R)}

Please respond honestly to all of the following questions. Your responses will be treated confidentially and anonymously.

1. With how many different partners have you had sex within the past 12 months?

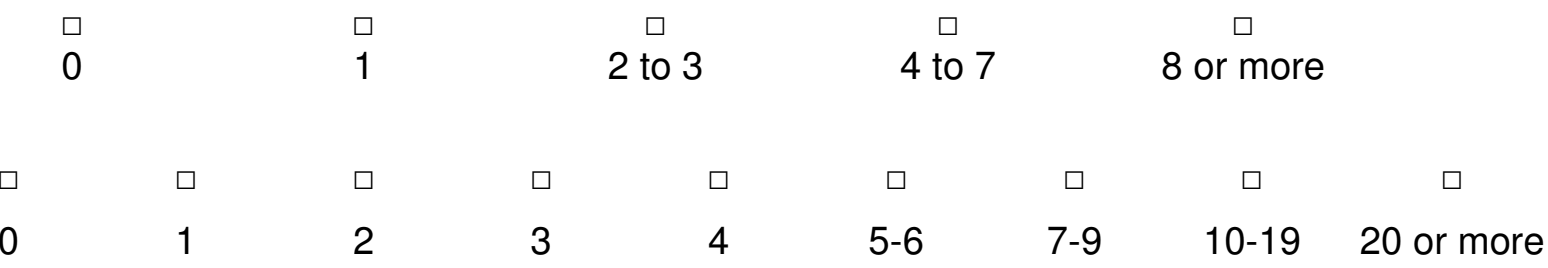

2. With how many different partners have you had sexual intercourse on one and only one occasion?

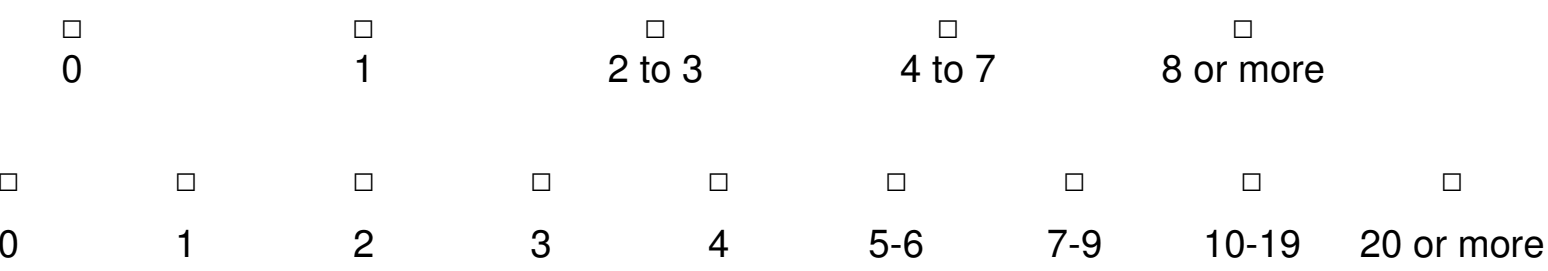

3. With how many different partners have you had sexual intercourse without having an interest in a long-term committed relationship with this person?

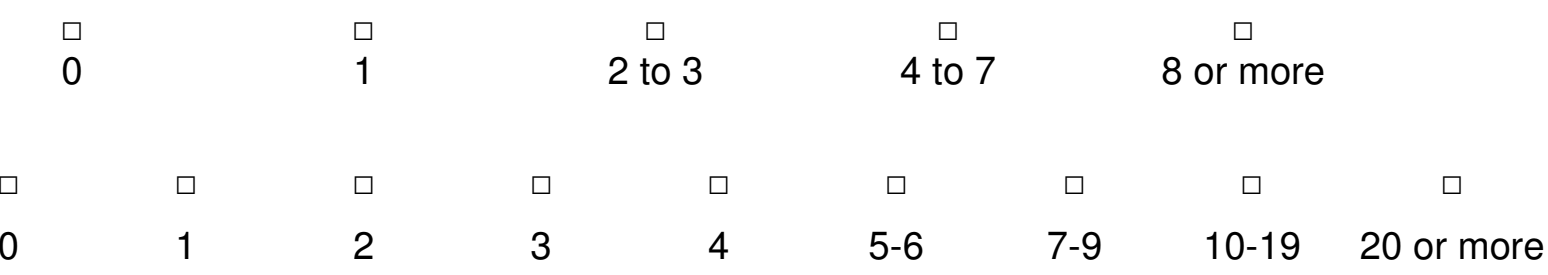

4. Sex without love is OK.

1 口

Totally disagree

1 ㄴ 2 ㅁ

3

4 ㅁ

5

$3 \square$

2 口
4

Strongly disagree
ㅁ 4 
5. I can imagine myself being comfortable and enjoying "casual" sex with different partners.

1 口

Totally disagree

$1 \square$

$2 \square$

$3 \square$

$4 \square$

$5 \square$

$6 \square$

$7 \square$

$8 \square$

Strongly agree

Strongly disagree

$3 \square$

4 ㅁ Totally agree

6. I do not want to have sex with a person until I am sure that we will have a long-term, serious relationship.

1 口

Totally disagree

$1 \square$

2 口

3 口
2 口

Strongly disagree

$3 \square$

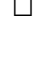

$5 \square$

$4 \square$

$6 \square$

$7 \square$

$8 \square$

Strongly agree

7. How often do you have fantasies about having sex with someone you are not in a committed romantic relationship with?
1 口
2 口
3 口
$4 \square$
$5 \square$
Never
Very seldom
About once a month
About once
week
Nearly every
day

\footnotetext{
$\square 1-$ never

$\square 2$ - very seldom

$\square 3$ - about once every two or three months

$\square 4$ - about once a month

$\square 5$ - about once every two weeks

$\square 6$ - about once a week

$\square 7$ - several times per week

$\square 8$ - nearly every day

$\square 9-$ at least once a day
} 
8. How often do you experience sexual arousal when you are in contact with someone you are not in a committed romantic relationship with?

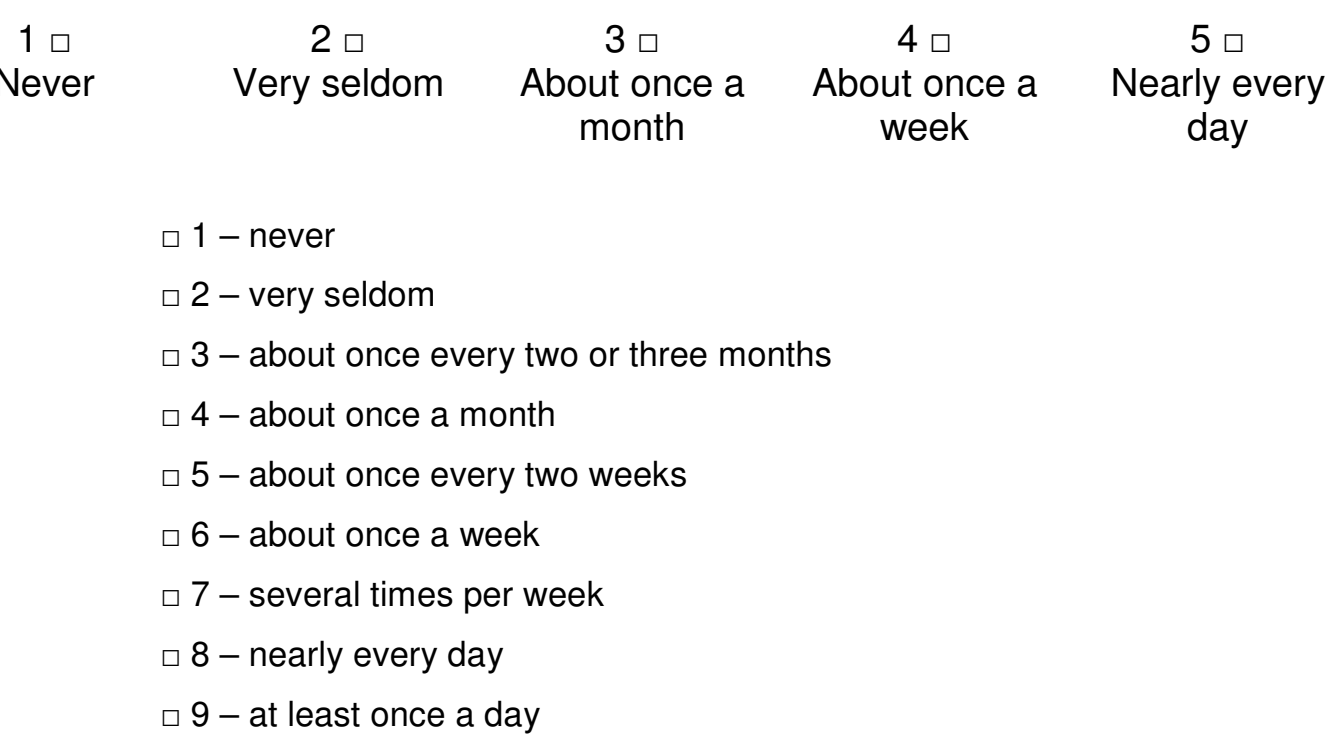

9. In everyday life, how often do you have spontaneous fantasies about having sex with someone you have just met?

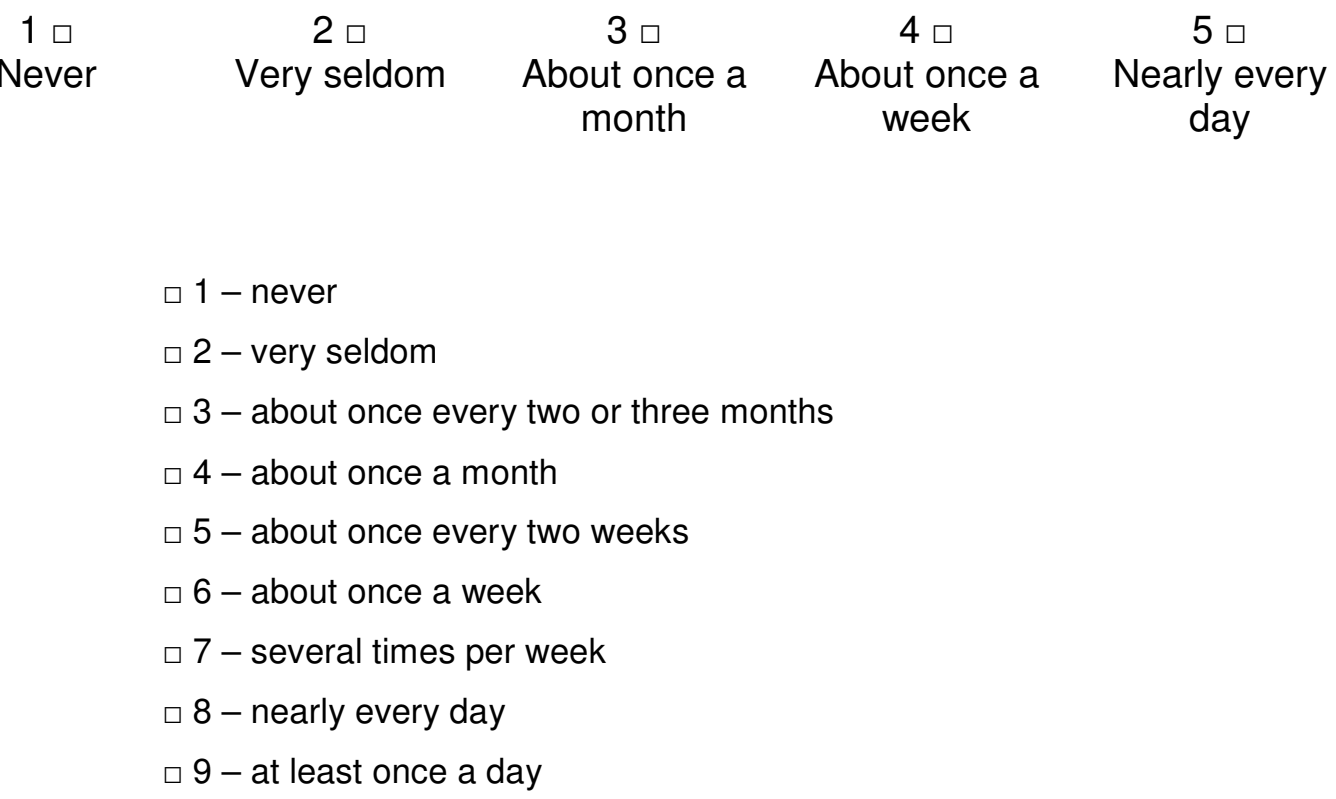

Source. This scale was originally published in "Beyond global sociosexual orientations: A more differentiated look at sociosexuality and its effects on courtship and romantic relationships" by L. Penke and J. B. Asendorpf, 2008, Journal of Personality and Social Psychology, 95, 1113-1135. Reprinted with permission. 